\title{
$O$ ato infracional e a prática jurídica processual: uma análise discursiva
}

\author{
The infractional act and the legal procedural practice: \\ a discursive analysis \\ Rubeilton Guilherme SALES* \\ Universidade Federal do Sul e Sudeste do Pará (Unifesspa) \\ Hildete Pereira dos ANJOS** \\ Universidade Federal do Sul e Sudeste do Pará (Unifesspa)
}

\begin{abstract}
RESUMO: A pesquisa propôs investigar as práticas discursivas no processo de ato infracional, objetivando identificar as formações discursivas e suas relações na trama discursiva de um processo judicial de ato infracional. Metodologicamente, mobilizou-se as teorias e procedimentos da análise de discurso a partir dos conceitos foucaultianos de discurso, formação discursiva, regularidade discursiva, enunciado, prática discursiva, memória discursiva. A partir da análise dos enunciados identificados no processo, à luz da literatura acerca da adolescência, da criminologia e sociologia, bem como da história dos direitos e das políticas de atendimento à criança e ao adolescente no Brasil, buscou-se as memórias discursivas mobilizadas e as regularidades dos enunciados, de modo a identificar as formações discursivas do "adolescente em perigo" e do "adolescente perigoso" e os respectivos discursos que, em sua coexistência, dão conformação a tais formações discursivas.
\end{abstract}

PALAVRAS-CHAVE: Ato infracional. Análise de discurso. Formação discursiva.

ABSTRACT: The research proposed to investigate the discursive practices in the process of infraction, aiming to identify the discursive formations and their relations in the discursive plot of a judicial process of an infraction. Methodologically, he mobilized the theories and procedures of discourse analysis from the Foucauldian concepts of discourse, discursive formation, discursive regularity, utterance, discursive practice and discursive memory. Based on the analysis of the statements identified in the process, in the light of the literature on adolescence, criminology and sociology, as well as the history of rights and child and adolescent care policies in Brazil, we sought the mobilized discursive memories and the regularity of the statements in order to identify the discursive formations of the "adolescent in danger" and the "dangerous adolescent" and the respective discourses that, in their coexistence, conform to such discursive formations.

KEYWORDS: Infractional act. Discourse analysis. Discursive formation.

\footnotetext{
* Mestre em Dinâmicas Territoriais e Sociedade na Amazônia, pelo Programa de Pós-Graduação em Dinâmicas Territoriais e Sociedade na Amazônia (PDTSA), da Universidade Federal do Sul e Sudeste do Pará (Unifesspa). Endereço eletrônico:rubeiltoneduc@ hotmail.com

** Doutora em Educação. Professora Associada da Faculdade de Educação (ICH), da Universidade Federal do Sul e Sudeste do Pará (Unifesspa) e Docente do Programa de Pós-Graduação e Dinâmicas Territoriais e Sociedade na Amazônia (PDTSA). Endereço eletrônico: anjoshildete@ unifesspa.edu.br
} 


\section{Introdução}

Neste trabalho apresentamos o resultado de uma pesquisa realizada durante o mestrado do Programa de Pós-graduação em Dinâmicas Territoriais e Sociedade na Amazônia, da Universidade Federal do Sul e Sudeste do Pará (Unifesspa), onde procuramos compreender as práticas discursivas no Processo Judicial de Ato Infracional. Tal instrumento tem, como objetivo jurídico-institucional, realizar a apuração de atos praticados por adolescentes. No caso, dada a condição de inimputabilidade dos sujeitos, estes são submetidos a procedimentos judiciais de apuração e julgamento diferenciados, bem como a responsabilização através de medidas socioeducativas.

O objeto de estudo sobre o qual debruçamos foi a produção discursiva existente no processo judicial de ato infracional. A partir dos textos dos diferentes documentos do processo, empreendemos a análise, lançando mão dos conceitos de regularidade discursiva, formação discursiva, memória discursiva, enunciado e função enunciativa de Foucault (2002a), buscando compreender a forma como os enunciados, em seu contexto e função enunciativa, mobilizam memórias discursivas, cujas regularidades permitem evidenciar a existência de formações discursivas (e as relações de coexistências entre elas) no âmbito do processo de ato infracional.

O caso cujo processo judicial serviu de corpus analítico da pesquisa trata de um adolescente de 17 anos que foi acusado, juntamente com uma pessoa adulta, de ter tramado o assassinato de um Policial Militar que se encontrava em estado de embriaguez, para roubar-lhe armas, dinheiro e produtos cosméticos.

A partir do acesso a uma literatura relacionada à adolescência, à criminologia, à sociologia jurídica, à história dos direitos e das políticas de atendimento à criança e ao adolescente no Brasil, bem como do estudo de produções sobre a Análise de Discurso, identificamos nos enunciados regularidades discursivas em um processo judicial de ato infracional, que apontam para a coexistência de duas formações discursivas: as quais denominamos (1) "adolescente em perigo" e (2) "adolescente perigoso". 


\section{As formas de criminalização ${ }^{1}$ e punição entre adultos e adolescentes no Brasil e as práticas discursivas}

As lógicas e formas de punição que constituíram o que compreendemos hoje como sistemas (sistema penal, sistema penitenciário, sistema de justiça juvenil, sistema socioeducativo, dentre outras nomenclaturas) tem por base as concepções, teorias e práticas penais surgidas em meados século XVIII, como a uniformização e individualização das penas e a predominância da prisão como forma de punição (FOUCAULT, 1987), sob o argumento da escola clássica da criminologia, da tipificação do crime e da aplicação da pena em nome da defesa da sociedade (BARATTA, 2002). Tais bases, por sua vez, tiveram como contexto histórico de origem a ascensão de uma classe (a burguesia) e as transformações ocorridas na economia, no desenvolvimento científico e, sobretudo, nas modificações das relações de poder.

Seguindo a tradição dos sistemas jurídico-penais ocidentais modernos e da contemporaneidade, o sistema penal brasileiro veio a se constituir de forma efetiva, a partir do século XIX, tendo herdado a estrutura dos sistemas europeus, apesar das diferenças culturais e econômicas. As condições históricas (políticas, econômicas e sociais) do Brasil, embora com suas especificidades, segundo Wacquant (1999), têm acompanhado a tendência dos países ocidentais, no que se refere às políticas de repressão da violência, a partir da segregação da miséria, com a política da tolerância zero.

Em se tratando do envolvimento de crianças e adolescentes em delitos penais, temos que estes, historicamente, têm estado em posição de desvantagem em relação aos adultos, no que se refere à criminalização de suas condutas e à punição. No período anterior ao surgimento do sentimento de infância (ARIÈS, 2006), eles participavam da vida social, praticamente, na condição de adultos, não fosse um detalhe: na sociedade de forte sentimento patriarcal, as crianças eram também objetos que se sujeitavam à violência e abusos dos adultos. Como as crianças e adolescentes eram indivíduos

\footnotetext{
${ }^{1}$ Consideraremos aqui o conceito de criminalização em Zaffaroni e Batista (2011), o qual a compreende duas dimensões: a primária, que se refere à definição dos atos e condutas como crimes, na elaboração das leis; e a secundária, que ocorre quando da atuação das instituições do sistema de justiça sobre o indivíduo (polícia, Ministério Público e Judiciário). Esta última se refere, então, a um processo de institucionalização pelo qual passa a pessoa suspeita de cometer um ato ilícito.
} 
destituídos de direitos, as ilicitudes (conduta reprovada pela família ou pela sociedade) e as punições (castigos) eram definidas pelos pais.

O Brasil, ao longo de sua trajetória, construiu um sistema de responsabilização de crianças e adolescentes a partir de três doutrinas jurídicas distintas: a do direito penal do menor, que utilizava a mesma legislação penal dos adultos, ressalvando apenas os casos de falta ou insuficiência de discernimento; da situação irregular do menor, de caráter assistencialista, que confundia proteção e punição; e a doutrina da proteção integral, que considera todas as crianças e adolescentes como sujeitos de direitos e distingue o que é medida de proteção e medida de responsabilização.

Trazendo a discussão para os dias atuais, temos que o tratamento dado à criança e ao adolescente autor de ato infracional tem sua origem no sistema penal. Em um primeiro momento, o sistema era o mesmo dos adultos; em um segundo momento, procurou-se dissociá-lo, contudo os princípios e as práticas continuaram os mesmos do sistema penal; e no terceiro momento (da doutrina da proteção integral), reconheceramse as condições das crianças de adolescentes e seus direitos à proteção especial, dividiram-se proteção e punição, mas, ainda assim, persiste, nas práticas institucionais de responsabilização, a predominância da lógica do sistema penal dos adultos.

As circunstâncias históricas da constituição do sistema de justiça juvenil, apontadas acima, são fundamentais para empreendermos uma análise da produção discursiva do processo judicial de ato infracional, identificando regularidades que remetem a formações discursivas, no âmbito dos discursos constantes dos autos de ato infracional.

\section{Analisando os enunciados nos textos documentais do processo}

Antes de discorrer sobre a análise dos enunciados, apresentaremos brevemente os principais conceitos da Análise do Discurso que serviram de base para a abordagem do objeto de pesquisa, os quais são fundamentais para a compreensão do estudo. Como anunciado nas páginas precedentes, apresentaremos tais conceitos a partir da perspectiva de Michel Foucault (1996, 2002a).

Foucault (2002a, p. 124) define como discurso um "conjunto de enunciados

que se apoiam em um mesmo sistema de formação”. Para ele, na construção dos discursos existem mecanismos e procedimentos de controle, seleção e organização 
inerentes às relações de poder e materialidade de suas condições de produção. $\mathrm{O}$ discurso nessa perspectiva, “[...] não é simplesmente aquilo que traduz as lutas ou os sistemas de dominação, mas aquilo por que, pelo que se luta, o poder do qual nos queremos apoderar" (FOUCAULT, 1996, p. 10).

O sistema de formação apontado por Foucault, ao definir conceitualmente o discurso, é a "formação discursiva". Foucault (2002a, p. 133-134) descreve a formação discursiva como "grupos de enunciados" que estão ligados entre si, constituindo-se no "sistema enunciativo geral ao qual obedece um grupo de "performances verbais"”. Nessa perspectiva, os enunciados são considerados pelo autor como as performances verbais que possibilitam as formações discursivas que darão origem aos discursos. O enunciado é uma produção em correlação com outras, participando de dados domínios, submetido, portanto, a determinadas regras de relação. Só podemos reconhecer o enunciado "pela análise das relações entre o enunciado e os espaços de diferenciação, em que ele mesmo faz aparecer as diferenças" (FOUCAULT, 2002a, p. 108).

Tais relações implicam em considerar também uma memória discursiva; o enunciado "abre para si mesmo uma existência remanescente no campo de uma memória", vinculando-se a "enunciados que o precedem e o seguem" (FOUCAULT, 2002a, p. 31-32). Empreender uma análise da prática discursiva ${ }^{2}$ na perspectiva foucaultiana exige, portanto, considerar a noção de regularidade discursiva: a recorrência de determinados enunciados cujos jogos de relações, em dadas condições de produção do discurso, constituem uma regularidade capaz de constituir uma formação discursiva.

Apresentados os conceitos que nos serviram de base para análise da prática discursiva do processo de ato infracional, vamos nos voltar agora para a descrição dos procedimentos de análises e os respectivos resultados obtidos.

A análise do corpus se deu, preliminarmente, a partir de um inventário dos enunciados que aparecem com mais frequência no texto dos principais documentos processuais (boletim de ocorrência, termo de representação, termos de audiência e oitiva, relatórios, despachos e sentença); e, em um segundo momento da análise,

\footnotetext{
2 Definida como "[...] um conjunto de regras anônimas, históricas, sempre determinadas no tempo e no espaço, que definiram, em uma dada época e para uma determinada área social, econômica, geográfica ou linguística, as condições de exercício da função enunciativa" (FOUCAULT, 2002a, p. 136).
} 
procuramos identificar enunciados utilizando um critério qualitativo, a partir das regularidades encontradas na análise preliminar.

Aprofundando nossa análise, pelos aspectos históricos e teóricos apresentados sobre a legislação e política de atendimento à criança e ao adolescente, até chegar na questão específica do ato infracional, permitimo-nos identificar duas formações discursivas distintas as quais, aproveitando-nos das expressões utilizadas por Rizzini (2011), denominaremos de formação discursiva do "adolescente em perigo" e formação discursiva do "adolescente perigoso". A primeira se constituiu das relações entre enunciados que mobilizam memórias e discursos relacionados ao reconhecimento do adolescente enquanto pessoa em desenvolvimento e detentor de direitos, de cidadania; e a segunda foi composta pelas relações entre enunciados que evocam a segregação, punição e responsabilização do adolescente em nome da defesa da ordem social.

Para a nossa empreitada, procuraremos a seguir analisar os enunciados no contexto enunciativo específico do texto processual, no intuito de identificar as regularidades discursivas, no acontecimento enunciativo, a mobilização dos discursos e a correlação existencial dessas duas formações discursivas, nos documentos do processo de ato infracional. As análises apresentadas abaixo serão apresentadas de forma resumida, uma vez que a dimensão deste trabalho não comporta a minúcia das análises presente no trabalho original.

\subsection{A produção discursiva na perspectiva da Polícia Civil}

Procuraremos neste tópico descrever a análise do que foi possível perceber na formulação discursiva presente nos textos dos documentos da ocorrência policial (depoimentos) e no relatório do Delegado de Polícia. Partindo dos princípios teóricos da $\mathrm{AD}$ a respeito da função do "dito" e do "não dito", analisaremos tanto os elementos discursivos que aparecem nos textos quanto aqueles que não aparecem textualmente.

Vejamos o enunciado (1), constante do depoimento do adolescente: 
(1) $\mathrm{O} \mathrm{Sr}$. [adolescente] acima qualificado às perguntas da autoridade [delegado] declarou: [...] ; QUE $^{3}$ o infrator afirma que na data de 04/07/2014 foi convidado pela vítima para assistir o jogo do Brasil em sua residência [...] ; QUE o infrator afirma que estava em companhia da vítima[...] ; QUE o infrator afirma que após o crime foi para a sua casa até ser preso por policiais militares [...] E nada mais disse e nem lhe foi perguntado, pelo que a Autoridade determinou o encerramento do presente termo, o qual lido e achado conforme, assina com o Adolescente em conflito com a lei, e comigo Escrivã que o digitei (grifo nosso).

O enunciado "infrator", enquanto acontecimento discursivo, constitui uma qualificação ao indivíduo (adolescente) que, supostamente, cometeu um ato infracional. O contexto da enunciação é de um escrivão que toma o depoimento do adolescente (a quem o ato infracional é atribuído), na apuração de um homicídio (não de qualquer um, mas de um policial), em uma delegacia, com o objetivo (institucional) de elucidar tal homicídio. O enunciado (como forma de identificação do acusado) se materializou, portanto, na escrita de um depoimento. Nas relação político-discursiva, o delegado pergunta, o adolescente responde (confessando o ato) e o escrivão registra. Ocorre que, ao registrar o depoimento, o escrivão, por questões técnicas, resume as respostas do adolescente. Para tanto, faz uso de outros termos, além dos ditos pelo depoente (adolescente), não transcrevendo a fala deste em sua íntegra. Ao fazer isso (a inferência de termos), mobiliza outros sentidos para o dito. No caso em questão do enunciado “infrator": 1) ao mesmo tempo que identifica a parte no ato do depoimento, qualifica-o enquanto culpado, ou seja, infrator é alguém que comete uma infração (não um suspeito), sendo que esse conceito mobilizado pode trazer, por exemplo, um sentido de parcialidade, por parte do escrivão; e 2) o mesmo enunciado também remete à infração penal que, por sua vez mobiliza toda uma memória discursiva relativa à criminalização e a punição, estando mais próximas do direito penal positivo do que dos princípios da proteção integral.

Para melhor identificarmos os sentidos do direito penal positivo, podemos relacionar o enunciado "infrator" com "crime" e "preso", na seguinte passagem: "[...] o infrator afirma que após o crime foi para a sua casa até ser preso por policiais militares [...]"4. Mais uma vez encontramos aqui enunciados que remetem a conceitos e práticas

\footnotetext{
3 "QUE", escrito em caixa alta é um recurso textual da escrita processual jurídica, utilizado pelo escrivão para indicar que se inicia a resposta a uma pergunta feita pelo delegado. Cada resposta se inicia com ponto e virgula e a expressão "QUE".

${ }^{4}$ Grifo nosso.
} 
do direito penal. Ao confrontarmos os enunciados "infrator", "crime" e "preso" com o "adolescente em conflito com a lei", percebemos que, embora enquanto termo ele seja capaz de mobilizar conceitos relacionados à proteção integral de crianças e adolescentes, enquanto acontecimento, no contexto enunciativo, não é capaz de reunir sentidos nessa direção. Apenas se apresenta uma única vez no depoimento (sem regularidade) cumprindo uma função enunciativa de identificação do depoente, ao relatar que o depoimento foi lido, conferido e assinado pelo delegado, pelo "adolescente em conflito com a lei” e pela escrivã.

Independentemente de quem tenha sido o enunciador de "crime" e "preso", isso não altera a perspectiva da regularidade discursiva, uma vez que os enunciados, em relação ao ato supostamente praticado pelo adolescente (o homicídio), mobilizam conceitos e sentidos que se relacionam a princípios, teorias e práticas sociais e institucionais cuja referência é o direito penal. São regularidades discursivas que se relacionam com uma concepção do adolescente enquanto criminoso.

No relatório do delegado, embora apareçam os termos técnicos previstos no ECA (apreensão e apreendido) para se referir a procedimentos em relação ao adolescente investigado por ato infracional, tais elementos aparecem sempre acompanhados de enunciados que mobilizam conceitos relacionados ao direito penal, surgindo aí, inclusive, o enunciado "menor em conflito com a lei", como pode ser identificado abaixo:

(2) Versa o presente Auto de Apreensão de Menor Infrator lavrado em situação de flagrância com o objetivo de apurar ato infracional [...] sendo que [o policial] ao chegar o menor já havia sido capturado por outra equipe policial [...] instante em que assumiu a custódia do menor apreendido[...] que [o policial] ao entrar em contato com o adolescente[...] este de pronto confessou a prática criminosa[...] esta autoridade policial apreendera o menor em conflito com a lei penal[...]. (trechos do relatório do inquérito policial).

É possível perceber, no trecho acima, uma tentativa de adequar a linguagem aos termos técnicos do ECA, contudo a prática discursiva institucional baseada no paradigma anterior permanece na prática judicial do agente, coexistindo com o modelo atual, resistindo a ele. Neste aspecto é importante ressaltar a existência de uma espécie 
de resistência aos mecanismos da interdição ${ }^{5}$ imposto pela legislação (ECA) e pelo debate político envolvendo a questão da infância e juventude.

Não podemos deixar de analisar, também, o que não aparece nos documentos policiais. Nos documentos analisados não aparecem enunciados que evidenciam a condição pessoal, social e familiar do adolescente (composição familiar, escolarização, profissionalização, relações de trabalho, saúde...). Em outros termos, não aparecem enunciados que apontem minimamente para a identidade social do indivíduo, o que coloca o adolescente apenas como ofensor (ou suposto ofensor). O foco está no ato antijurídico e suas consequências para a lei, para a ordem, o que conduz ao caracterizado por Baratta (2002) como direito penal clássico, onde o que importa é o crime a sua punição, em nome da defesa da sociedade.

Talvez pareça simples questionar as análises realizadas até aqui com argumentos de que o papel da polícia judiciária é prender e acusar (isso justificaria essa regularidade discursiva). Contudo, argumentos como estes (do senso comum) não se sustentam: primeiro porque o papel institucional da polícia, sobretudo a judiciária, não é prender e nem acusar, mas investigar, apurar, procurar identificar o crime (no caso do adulto) e o ato infracional (no caso do adolescente) e o seu autor, garantindo os direitos dos cidadãos; segundo porque, em se tratando de ato infracional supostamente praticados por adolescentes, o Estatuto da Criança e do Adolescente (ECA) prevê a garantia do respeito à sua condição de pessoa em condição peculiar de desenvolvimento, da qual decorrem vários outros direitos, que deveriam se materializar na forma de tratamento do adolescente e, consequentemente, refletir na produção discursiva.

\subsection{A produção discursiva na perspectiva do Ministério Público}

Devido ao desfecho da apuração processual ${ }^{6}$, a análise da produção discursiva do Ministério Público ficou restrita aos termos de declarações e ao termo de

\footnotetext{
5 A interdição, no sentido apontado por Foucault (1996), a que nos referimos, é a tentativa de silenciamento do enunciado "menor" imposto pelo ECA, ao substituí-lo pelos termos criança e adolescente, bem como da substituição de termos processuais penais, como "crime", por ato infracional.

${ }^{6} \mathrm{O}$ fato de ter aparecido uma outra pessoa, adulta, que confessou ter praticado o homicídio, os documentos do Ministério Público produzidos especificamente sobre o caso do adolescente acabaram se restringindo aos termos de declaração do adolescente e de sua genitora e ao termo de representação, não tendo, por exemplo, o Ministério Público sustentado as acusações, em alegações finais.
} 
representação. Contudo, ainda é possível analisar alguns aspectos. Comecemos pelo termo de declaração prestado pela genitora do adolescente.

Primeiramente, é importante ressaltar que no "Termo de Declaração" prestado pela mãe do adolescente, o adolescente é sempre identificado pelo seu nome, como se acompanha em (3):

(3) [...] QUE é genitora do adolescente[nome do adolescente]; QUE [nome do adolescente] saiu, junto com a declarante; [...] QUE [nome do adolescente] negou tê-los matado, mas ficou tranquilo; [...] QUE colocaram [nome do adolescente] no carro e foram a delegacia; [...] QUE foi a delegacia, onde viu [nome do adolescente]com o olho inchado;[...].

Observamos nos trechos das declarações prestadas pela mãe do adolescente que, ao contrário do que ocorreu com os documentos da polícia, não houve inferência de termos de identificação da pessoa do adolescente que viessem a se constituir enunciados capazes de produzir efeitos de sentido relacionados à sua criminalização. $\mathrm{O}$ adolescente é sempre identificado pelo seu nome.

Se considerarmos o nome do adolescente como enunciado, ou seja, que, além de um nome de uma pessoa, é um acontecimento discursivo que mobiliza, no contexto enunciativo, o adolescente enquanto pessoa, a sua situação perante a lei e um momento de relação e intervenção institucional, poderemos perceber que esses elementos discursivos presentes constituem uma regularidade enunciativa (marcada pela utilização do nome do adolescente enquanto enunciado) que traz efeitos de sentido mais inclinados a uma imparcialidade institucional, na apuração dos fatos.

No "Termo de Oitiva e Entrega de Adolescente", também, não há a inferência de termos ou enunciados de identificação mobilizadores de sentidos que venham a se relacionar com a criminalização penal. O nome do adolescente aparece poucas vezes, sendo que, na maioria do texto, aparecem somente as respostas do adolescente, sem nome ou qualquer outro termo identificador:

(4) [...]Após, procedeu-se a oitiva do adolescente o qual disse: QUE estava assistindo a partida do Brasil [jogo da seleção Brasileira] em sua residência[...]; QUE após a partida foi para a casa da vítima[...]; QUE a casado policial [a vítima] estava lotada, onde todos estavam ingerindo bebida alcoólica; [...]que o policial [a vítima] o convidou para ir ao [danceteria], local de festa, à noite, onde ele foi; [...] QUE [conhecido do adolescente] não comentou nada com o adolescente [nome do adolescente]sobre matar o policial; [...].(grifo nosso) 
Como pode ser evidenciado acima, na transcrição das declarações, não constam enunciados que possam constituir, no particular, uma regularidade discursiva que possibilite a identificação de uma formação discursiva relacionada especificamente ao adolescente em conflito com a lei, enquanto "adolescente "perigoso". Já no texto do "Termo de representação do adolescente", que não se trata de transcrição de depoimentos ou tomada a termo de declarações (mas a descrição do ato, a fundamentação legal e o pedido de apuração ao judiciário), são utilizados termos que, no contexto enunciativo, podem fazer referência a alguma dessas formações discursivas (ou a ambas).

(5) [...] na residência da vítima, o infrator [nome do adolescente], em concurso com outros indivíduos maiores, suprimiu a vida da vítima[...] utilizando-se de uma arma de fogo, tipo revolver, atingindo-o com um disparo na região frontal do crânio.

(5A) Ocorre que, durante a festa, o adolescente infrator foi abordado por um dos comparsas conhecido por [nome do outro acusado] que, observando a vítima estar interessada no adolescente, orientou este a levar a vítima para a residência dela e lá, matar a vítima com um tiro na testa[...]

(5B) [...] a vítima adormeceu, instante em que o representado executando o plano criminoso arquitetado pelo comparsa [nome da pessoa que planejou o ato], empunhou a própria arma da vítima e encostou o cano da arma na fronte do ofendido e disparou um tiro fatal (grifo nosso).

Nos trechos transcritos acima, extraídos do documento da representação do Ministério Público, é possível perceber que, ao contrário do que ocorreu nos textos dos documentos da polícia, o mecanismo da interdição imposta pelo ECA se mostrou em pleno funcionamento: os enunciados utilizados para a identificação da pessoa do adolescente, pelo promotor de justiça, foram "infrator", "representado", "adolescente infrator" e "adolescente". O enunciado "infrator" remete à infração penal, mas também remete a ato infracional. "Representado" remete à representação, o seu próprio instrumento jurídico, segundo o ECA. Dessa forma, não há que se questionar uma postura discursiva "politicamente correta", uma vez que não foram utilizados termos abolidos pelo ECA.

Ao analisarmos, porém, os enunciados e seus aspectos discursivos, podemos enxergar outros elementos. Consideremos, agora de forma mais detalhada, os enunciados constantes dos trechos transcritos acima: 
(6) $[\ldots]$ o infrator [nome do adolescente] em concurso com outros indivíduos maiores, suprimiu a vida da vítima[nome da vítima] utilizandose de uma arma de fogo, tipo revolver, atingindo-o com um disparo na região frontal do crânio (grifo nosso).

Na primeira parte do enunciado (6), que menciona que o adolescente "[...] em concurso com outros indivíduos maiores, suprimiu a vida da vítima [...]”, o termo "maiores" mobiliza o conceito de "menor" que, embora não apareça textualmente, apresenta-se no discurso do promotor. Outro conceito é mobilizado e, com ele, o discurso onde faz sentido, predominado aqui aqueles referentes ao adolescente enquanto indivíduo perigoso. Analisando a enunciação abaixo, utilizada pelo promotor para justificar a Representação do adolescente ao judiciário, podemos identificar melhor os sentidos mobilizados:

(7) [...] a vítima adormeceu, instante em que o representado executando o plano criminoso arquitetado pelo comparsa [nome da pessoa que planejou o ato], empunhou a própria arma da vítima e encostou o cano da arma na fronte do ofendido e disparou um tiro fatal (grifo nosso).

A descrição minuciosa do ato inclina para uma condenação do ato praticado, ao mesmo tempo que questiona a conduta, os valores e a pessoa do autor. Ao mencionar que o adolescente agiu "executando um plano criminoso", acaba-se evocando a palavra "crime", ao qualificar o adolescente e o incluir em uma categoria de indivíduos que afrontam a lei. Tal movimento discursivo, do ponto de vista do papel institucional do Ministério Público é aparentemente aceitável, se considerarmos que se trata de um discurso de fundamentação de uma acusação. Contudo, se considerarmos que se trata especificamente da representação de um adolescente por ato infracional, indivíduo do qual o Ministério Público também tem como atribuição promover a defesa (através da garantia de seus direitos legais dentre os quais a sua distinção no atendimento entre o adolescente e o adulto), podemos enxergar outros aspectos.

Podemos perceber que, ao realizar a criminalização da conduta do adolescente, a produção discursiva evidencia a "periculosidade" do indivíduo. Ao mencionar que "a vítima adormeceu", abre-se a possibilidade de se considerar que o adolescente em seu ato foi covarde, traiçoeiro, que se aproveitou do momento em que a vítima estava indefesa para cometer o ato. Ao especificar que o adolescente cometeu o ato com "a própria arma da vítima" e disparando "um tiro fatal", realça-se a capacidade ofensiva e 
violenta do autor do ato. A presença desses elementos no discurso demonstra não só uma simples estratégia jurídica de imputação de um crime a uma pessoa (comum da justiça criminal dos adultos) ${ }^{7}$, mas, também, produz efeitos de sentido que atribuem ao autor do fato, ou seja, ao adolescente, uma identificação de indivíduo perigoso.

\subsection{A produção discursiva na perspectiva do Judiciário}

Passaremos agora à análise discursiva a partir dos textos dos documentos produzidos pelo Poder Judiciário, no decorrer do processo de apuração do ato infracional. Tais análises se darão a partir dos textos dos despachos, termos de audiência, decisões e sentença. Procuraremos seguir a mesma dinâmica de análise adotada até aqui.

Inicialmente analisaremos dois despachos do juiz que se encontrava de plantão e que recebeu o flagrante e decretou a internação provisória do adolescente. O primeiro homologa o flagrante e concede vistas ao Ministério Público para se manifestar sobre a representação do adolescente, enquanto no segundo despacho, recebe-se a representação do Ministério Público e determina-se a sua internação em caráter provisório. Vejamos, nos excertos (8), (8A) e (8B), a transcrição dos principais trechos dos despachos:

(8) A autoridade policial comunicou o flagrante em desfavor do adolescente em epígrafe, relatando os fatos que propiciam na conclusão dos indícios da prática do ato infracional pelo infante, vez que testemunhas informaram sobre o ocorrido, apontando o adolescente como um dos autores do ato infracional (art. 157, $\S 3^{\circ}$, parte final CPB).

(8A)O adolescente foi detido após a ocorrência dos fatos e não há descontinuidade de tempo até a remessa dos autos a este Juízo o que permite a homologação de flagrante.

(8B)Encaminhem-se os autos ao Ministério Público para se manifestar sobre a representação em desfavor do adolescente. (Despacho de homologação do flagrante; grifo nosso).

Agora, vejamos abaixo, trechos do outro despacho, do mesmo juiz, após receber a representação do Ministério Público, no qual o magistrado acatou o pedido e determinou a internação provisória:

\footnotetext{
${ }^{7}$ Conforme aspectos destacados por Magri (2009), sobre a produção da verdade jurídica no campo discursivo do Direito.
} 
(9) O Ministério Público requer a internação do menor em epígrafe, em vista de protegê-lo de eventuais riscos para sua integridade física e por representar ameaça às testemunhas que presenciaram o ato infracional equiparado ao crime de latrocínio e (art. $157, \S 3^{\circ}$, parte final do CP).

(9A) [...] narra o membro do parquet [Ministério Público] que o menor juntamente com outro arquitetou o plano e o executou, disparando contra a vítima e após subtraiu seus pertences, conforme depoimentos nos autos [...] (9B)Nos autos há testemunhos que sustentam os indícios de autoria do ato infracional pelo menor.

(9C)O fato de ser adolescente não autoriza a isenção de reprimenda e mais importante se faz no presente caso em que foi ceifada a vida da vítima, $\mathbf{e}$ se não houver resposta da justiça, o adolescente infrator interpretará como consentimento para cometer outras infrações análogas a condutas criminosas.

(9D)Isto posto, presentes os indícios de autoria e materialidade da infração[...] DETERMINO a internação provisória do adolescente pelo prazo de quarenta e cinco dias [...]. (Despacho de recebimento da representação e da internação provisória; grifo nosso).

Analisando os termos que aludem à identificação do adolescente no processo, podemos, de imediato, perceber que não aparece o termo "menor" ou outro termo que remeta à identificação do adolescente enquanto criminoso ou pessoa perigosa. Ao contrário, em alguns enunciados até se procura evitar isso, como, por exemplo, no enunciado "[...] comunicou o flagrante em desfavor do adolescente [...]", onde se procura, aparentemente, evitar o uso de "contra o adolescente", demonstrando aí a existência de uma interdição. Ao mesmo tempo em que podemos identificar um mecanismo de interdição nos enunciados deste primeiro despacho, podemos também perceber a resistência à interdição imposta pelo ECA: em "[...] O adolescente foi detido após a ocorrência dos fatos [...]". O termo "detido" remete à pena de detenção, prevista no Código Penal. Ocorre que ao adolescente não se aplica pena e sim medida socioeducativa, tendo o Estatuto da Criança e do Adolescente substituído "detenção" por "apreensão".

Voltando nossas análises para o segundo despacho, podemos perceber que o termo "menor" aparece três vezes enquanto identificador do adolescente. Uma regularidade enunciativa que contrasta com a do primeiro despacho. Mais que a frequência desse termo, é interessante atentarmos para a aparição deste nos enunciados.

No enunciado (9), “O Ministério Público requer a internação do menor em epígrafe, em vista de protegê-lo de eventuais riscos para sua integridade física e por representar ameaça às testemunhas que presenciaram o ato infracional [...]”, aparece uma dúbia conformação discursiva: uma que remete aos discursos e práticas da “doutrina do menor em situação da situação irregular (do Código de Menores), aludindo 
àquela concepção de segregar para proteger; e outra que remete às próprias teorias liberais clássicas da criminologia (BARATTA, 2002), que apresentam tal segregação como forma de retirar um indivíduo perigoso do convívio social, em nome da defesa da sociedade. Ao enunciar, em (9C) “[...] e se não houver resposta da justiça, o adolescente infrator interpretará como consentimento para cometer outras infrações análogas a condutas criminosas[...]”, o magistrado enfatiza tal concepção, mobilizando todo um campo discursivo do direito penal clássico.

É possível perceber, também, que o termo adolescente só aparece nos enunciados que remetem ao ECA. No enunciado (9C) "O fato de ser adolescente não autoriza a isenção de reprimenda[...]", os efeitos de sentido podem remeter à contestação de uma suposta proteção exacerbada concedida pelo ECA, a qual precisa ser questionada no momento da fundamentação da internação do adolescente. E no enunciado (9D) “[...] DETERMINO a internação provisória do adolescente [...]”, também faz-se alusão ao dispositivo previsto no estatuto.

Comparando os enunciados dos dois despachos, percebemos um contraste significativo, no que se refere à mobilização de diversos discursos. No primeiro despacho é possível perceber o mecanismo de interdição imposto pela legislação atual (ECA), baseada nos princípios da proteção integral, enquanto, no segundo despacho, já aparecem enunciados que mobilizam conceitos e princípios relativos ao direito penal e à doutrina do menor em situação irregular.

Vejamos agora alguns enunciados constantes nos termos de audiência. As audiências foram presididas por outro magistrado, uma juíza. Ater-nos-emos, principalmente, à audiência de apresentação do adolescente, uma vez que é nessa audiência que se desenvolve uma relação mais direta entre os enunciadores envolvidos no processo de ato infracional, o adolescente e o ato em si.

Inicialmente podemos perceber uma qualificação um pouco mais completa sobre o adolescente:

(10) Passou o MM. Juiz a ouvir o adolescente [nome do adolescente], natural de campestre/PA [...] que às perguntas respondeu: "Que tem 17 anos; que estuda na escola [nome da escola] no horário noturno; Que durante o dia faz curso no PRONATEC; Que faz curso de vendedor; Que mora com sua mãe; Que tem 4 irmãos; que seu pai não mora aqui; que não conhece o seu genitor [...] (trecho do termo de audiência de apresentação do adolescente) 
Podemos observar no trecho acima que os enunciados ${ }^{8}$ nele contidos demonstram uma maior preocupação em saber quem é o adolescente a quem se atribui o ato infracional, de conhecer suas origens, sua comunidade e as suas práticas sociais. Em outras palavras, estes enunciados remetem aos conceitos e princípios de que são importantes e devem ser consideradas as condições sociais e identitárias do adolescente na apuração do ato infracional, aspectos que remetem à doutrina da proteção integral, como, por exemplo, o previsto no artigo 121 do ECA, ao estabelecer o “[...] respeito à condição peculiar de pessoa em desenvolvimento."

\section{Considerações finais}

Ao longo das análises realizadas nas especificidades das produções discursivas das diferentes instituições sobre o caso de ato infracional abordado neste estudo, foi possível perceber diferenças e similaridades que, guardadas as devidas proporções do papel institucional e da constituição dos seus agentes enquanto indivíduos históricos e sujeitos do discurso (na medida das relações de poder estabelecidas no contexto enunciativo) merecem ser destacadas. Na literatura sobre a história das políticas de atendimento e da legislação sobre os direitos da criança e do adolescente no Brasil, as próprias noções e conceitos de infância e adolescência decorrentes dessas práticas institucionais e das conformações legais apontam para a coexistência de discursos que vinculam condições às crianças e adolescentes no sentido de um indivíduo incapaz. Indivíduo esse que, por não ter completada a sua formação, ora está vulnerável no âmbito social, ora constitui uma ameaça à sociedade.

Para melhor compreendermos esses aspectos dos discursos mobilizados, retomemos aqui algumas questões apresentadas por Foucault (1987), como o da punição como forma de reconstituição do pacto social e de criação de um ser obediente, onde as formas de controle e de disciplinamento dos indivíduos, adotadas pelo Estado, ao mesmo tempo em que impõem seu poder institucional, criam resistências contra a sua própria estrutura. Neste caso é importante compreendermos que os enunciados analisados emergem de um contexto de disputas de poder (FOUCAULT, 1979), que vai

\footnotetext{
${ }^{8}$ Entendemos que o enunciado pode se constituir tanto a partir da enunciação de uma única palavra, quanto de uma frase ou ainda um parágrafo, a depender da forma como ocorre o acontecimento discursivo. No caso em questão, referimo-nos a enunciados (no plural) porque, no trecho acima, foram retirados de diferentes pontos do depoimento e independentemente de ordem cronológica da enunciação, de modo que constituem diversos enunciados.
} 
além do caso estudado, se estendendo à relação indivíduo-sociedade-Estado, onde, muitas vezes, o ato contrário à lei, que é considerado atentatório à ordem, se configura em estratégias de resistência dos indivíduos face ao modelo de sociedade no qual estão inseridos, cujos respectivos mecanismos disciplinares e de controle geram a tensões e disputas nas relações de poder.

As questões identificadas neste estudo poderão ser mais bem compreendidas se tomarmos os elementos discursivos vislumbrados em nossas análises sobre o processo de ato infracional, partindo do princípio de que os enunciados surgem de uma conjuntura de disputa de poderes (FOUCAULT, 1979), onde o indivíduo agiu de forma a resistir à estrutura, às normas sociais de conduta e as instituições do Estado; por sua vez, tais instituições reagiram fazendo o enfrentamento, de modo a controlar esse indivíduo (através da disciplina e da sanção). Nesse contexto, não podemos deixar de considerar que a enunciação acontece sob controle de mecanismos de exclusão do discurso (FOUCAULT, 1996): há os processos de interdição (onde as partes, pelo contexto enunciativo, regulam o discurso falando de determinada forma, selecionando o que falam, silenciando-se em relação a outras); há a busca pela racionalidade e pela coerência do discurso de modo a torná-lo lógico (segregação da loucura); e há a busca incessante pela verdade dos fatos (vontade de verdade).

$\mathrm{O}$ adolescente, ao negar a autoria do ato (sem entrar no mérito dos motivos e interesses), se posiciona enquanto enunciador, com o seu poder (de inimputável, de pessoa em desenvolvimento e detentor de direitos e garantias processuais) em oposição à ação institucional, cujo poder (de agir em defesa da lei, de apurar, de cercear em defesa da sociedade ou do próprio adolescente) atribui a autoria da prática da infração ao adolescente e o coloca na condição de representado. A partir dessas posições os indivíduos enunciadores elaboram seus discursos que, como vimos, mobilizam outros discursos, outros sentidos que, ao se confrontarem com o contexto enunciativo do ato infracional em questão, produzem novos sentidos.

Através da análise discursiva do processo de ato infracional que foi objeto do presente estudo, foi possível apontar a existência de duas formações discursivas (entendendo o conceito do ponto de vista foucaultiano, como rede de dispersões) em relação ao adolescente em conflito com a lei: uma primeira formação discursiva que reunia os discursos do "adolescente em perigo" e uma segunda, do "adolescente 
perigoso". A formação discursiva do "adolescente perigoso" se apresenta de forma aparentemente mais evidente, seja pela aparição de enunciados que fazem referência às práticas anteriores à doutrina da proteção integral, seja pelas enunciações que mobilizam sentidos relacionados aos princípios e conceitos da criminologia e do direito penal. Contudo, a formação discursiva que alude ao adolescente "em perigo" também se apresenta de forma significativa ${ }^{9}$, em permanente confronto com a formação discursiva anterior, podendo ser observada no mecanismo da interdição, na conjugação de enunciados que remete a discursos distintos ("menor em conflito com a lei", por exemplo), e na utilização, na produção discursiva de todas as instituições, dos enunciados que se referenciam tanto na doutrina do menor em situação irregular quanto da proteção integral.

Os elementos e relações discursivas identificadas nas análises dos diferentes documentos (das diferentes instituições) conduzem-nos à coexistência do antigo (clássico), do anterior (revogado) com o atual (em vigor), no que se refere à legislação e às práticas institucionais do atendimento ao adolescente em conflito com a lei. A atual legislação impõe uma doutrina (a da proteção integral) e, entre seus elementos, normatiza uma "interdição" enquanto mecanismo discursivo, ao abolir a utilização de termos que se relacionam com uma estrutura legal e de políticas públicas de atendimento anteriores ao atual ordenamento jurídico, como os termos "menor", “crime", entre outros. Contudo, ao enunciá-los com regularidade ou omiti-los, através do não-dito ou por força de mecanismos de interdição, mobilizam os discursos do antigo em coexistência com o novo, demonstrando que as práticas sociais, institucionais e as concepções acerca do adolescente em conflito com a lei seguem o paradoxo da incapacidade (de cuidar de si) versus capacidade (de praticar violência), da proteção (a um indivíduo incompleto, em formação) versus a responsabilização (de um indivíduo violento).

\footnotetext{
${ }^{9}$ Sobretudo se considerarmos os aspectos da dispersão dos enunciados (FOUCAULT, 2002a), em seu contexto enunciativo onde, entre o "dito" e o "não dito", estes podem mobilizar sentidos e discursos dos mais diversos, como, por exemplo, a recorrência dos enunciados "menor" e "adolescente", que pode mobilizar tanto uma quanto a outra formação discursiva.
} 


\section{REFERÊNCIAS}

ARIÈS, P. História Social da Criança e da Família. Tradução de Dora Flaksman. $2^{\mathrm{a}}$ Ed. Rio de Janeiro: LTC, 2006.

BARATTA, A. Criminologia Crítica e Crítica do Direito Penal. Tradução de Juarez Cirino dos Santos. $3^{\text {a }}$ Ed. Rio de Janeiro: Editora Revan: Instituto Carioca de Criminologia, 2002.

BRASIL. Estatuto da Criança e do Adolescente. Lei Federal no 8069, de 13 de julho de 1990. Disponível em:< http://www.planalto.gov.br/ccivil_03/leis/L8069.htm.> Acesso em 27 dez. 2015.

FOUCAULT, M. A Arqueologia do Saber. Tradução de Luis Felipe Baeta Neves. $6^{\text {a }}$ Ed. Rio de Janeiro: Forense Universitária, 2002a.

FOUCAULT, M. A verdade e as formas jurídicas. Tradução de Roberto C. de Melo Machado e Eduardo Jardim Morais. Rio de Janeiro: NAU Editora, 2002 b.

FOUCAULT, M. A ordem do discurso. São Paulo, Loyola, 1996.

FOUCAULT, M. Microfísica do poder. 8. ed. Rio de Janeiro: Graal, 1979.

FOUCAULT, M. Vigiar e punir: o nascimento da prisão. Tradução de Raquel Ramalhete. Petrópolis: Vozes, 1987.

MAGRI, M. V. Efeitos de Verdade, Ethos e Relações de Poder no Discurso Jurídico. (Dissertação de Mestrado). Programa de Pós-Graduação em Linguística da Universidade Federal de São Carlos: São Carlos-SP, 2009.

RIZZINI, I. Meninos Desvalidos e Menores Transviados: a trajetória da assistência pública até a Era Vargas (225-286). In: RIZZINI, I; PILOTTI, F. (Orgs.). A Arte de Governar Crianças: a história das políticas sociais, da legislação e da assistência à Infância no Brasil. $3^{\text {a }}$ Ed. São Paulo: Cortez, 2011.

Trad. André Telles. 1999. Disponível em: < http://webcache.googleusercontent.com/search?q=cache:p59FEb_JetAJ:files.femadireit o102.webnode.com.br/20000003962f056357d/As\%2520Prisoes_da_Miseria\%2520Loic _Wacquant.pdf+\&cd=4\&hl=pt-BR\&ct=clnk\&gl=br >. Acesso em: 12 Ago 2015.

ZAFFARONI, E. R.; BATISTA, N. Direito Penal Brasileiro - I. 4. ed. Rio de Janeiro: Revan, 2011. 